\title{
Trauma Surgery \& Acute Care Open \\ Acute traumatic injuries of the adrenal gland: results of analysis of the Pennsylvania trauma outcomes study registry
}

\author{
Jody C DiGiacomo —ㄱ, Noam Gerber, L D George Angus, Swapna Munnangi, \\ Sara Cardozo-Stolberg
}

\begin{abstract}
- Additional material is published online only. To view please visit the journal online (http://dx.doi.org/10.1136/ tsaco-2020-000487).
\end{abstract}

Surgery, Nassau University Medical Center, East Meadow, New York, USA

Correspondence to Dr Jody C DiGiacomo; jdigiac1@ numc.edu

Received 10 April 2020 Revised 17 June 2020 Accepted 6 July 2020 (c) Author(s) (or their employer(s)) 2020. Re-use permitted under CC BY-NC. No commercial re-use. See rights and permissions. Published by BMJ.

To cite: DiGiacomo JC Gerber N, Angus LDG, et al. Trauma Surg Acute Care Open 2020:5:e000487.

\begin{abstract}
Background Blunt injuries to the adrenal glands are considered rare, associated with severe injury, and highly mortal, based on autopsy series and earlier retrospective reviews. Recent studies have reported higher incidence rates associated with lower injury severity and mortality rates.

Methods A 3-year review of the Pennsylvania Trauma Outcomes Study Registry of adults with intra-abdominal injuries after blunt trauma was performed and associated organ injuries, injury parameters and in-hospital mortality were compared between those with and those without adrenal gland injury.

Results 5679 patient records were identified, 439 with adrenal gland injuries and 5240 without. The liver and the kidney were the intra-abdominal organs most frequently associated with injuries to an adrenal gland, and the spleen was the intra-abdominal organ most frequently injured in those without an adrenal gland injury. There was no difference in mortality rates.

Discussion Injuries to the adrenal gland occur with an incidence of $0.43 \%$ after blunt force trauma. The presence of a blunt adrenal gland injury is not a marker of severe injury or associated with an increased mortality rate.

Level of evidence II, Retrospective Study.
\end{abstract}

\section{BACKGROUND}

Although blunt injury of an adrenal gland is uncommon, it is not nearly as rare as previously thought. ${ }^{1-7}$ We previously reported a retrospective review of our urban Level 1 trauma center's 15 -year experience with adrenal gland injuries using a matching estimator technique which casematched patients with adrenal gland injuries to acutely injured patients without adrenal gland injuries. ${ }^{1}$ That analysis went beyond the basic statistical analyses of previous retrospective reviews by estimating the influence of adrenal gland injuries on mortality and concluded that adrenal injuries are not significant to the overall outcome of the patient. ${ }^{1}$ The conclusions of that research stood in opposition to previous case series which concluded that adrenal injuries were rare and were associated with a high mortality rate and degree of injury. ${ }^{2-6}$ That variance of conclusions prompted us to investigate our State's larger trauma database, the New York State trauma registry (NYSTR), which supported our previous findings that the incidence of blunt adrenal gland injury is much higher than the $0.04 \%$ to $0.24 \%$ incidence that had been previously reported..$^{2-7}$ Inasmuch as the data in our initial investigation from our single institution are contained within the NYSTR dataset used in our follow-up investigation, this study was undertaken to assess whether the conclusions of our previous studies, that blunt adrenal gland injuries are not associated with increased severity of injury or increased mortality rates, are supported using a different statewide trauma registry.

\section{METHODS}

\section{Data source}

A retrospective cohort study was conducted using data from the Pennsylvania Trauma Outcomes Study (PTOS) Registry from 2012 through 2014 (3 years) which was provided by the Pennsylvania Trauma Systems Foundation, Mechanicsburg, Pennsylvania, USA. The Foundation specifically disclaims responsibility for any analyses, interpretations, or conclusions. The PTOS is a statewide data repository that collects medical record information on all trauma patients managed at Level I to IV trauma centers in the state of Pennsylvania. Patients with solitary hip fracture, asphyxiations, hypo/hyperthermia, drownings, poisonings, and in-hospital injuries are excluded from the PTOS registry. ${ }^{8}$ Data collected in the PTOS include demographics, prehospital information, process of acute care information, clinical data, outcome data, diagnoses, procedures, and payor class information. ${ }^{8}$

\section{Study cohort selection (inclusion and exclusion criteria)}

Patients 18 years of age or older with primary "blunt-type" injury and an abdominal organ injury based on International Classification of Diseases, 9 Revision, Clinical Modification (ICD-9-CM) codes were selected for inclusion for this study (online supplementary figure 2). Exclusions are detailed in online supplementary figure 3 .

\section{Variables of interest}

The exposure of interest was the presence of a blunt adrenal gland injury as identified by ICD-9-CM code 868.01. Additional patient characteristics that were extracted included age, gender, primary mechanism of injury, Injury Severity Score (ISS), Revised Trauma Score (RTS), the Glasgow Coma Scale Score (GCS) at admission, vital readings at admission (eg, pulse rate, respiratory rate, and systolic 
Table 1 Comparison of characteristics between patients with and without an adrenal gland injury

\begin{tabular}{|c|c|c|c|}
\hline & \multicolumn{2}{|c|}{ Abdominal injury } & \multirow[b]{2}{*}{$P$ value } \\
\hline & $\begin{array}{l}\text { Adrenal gland } \\
\text { injury present } \\
(n=439)\end{array}$ & $\begin{array}{l}\text { No adrenal gland } \\
\text { injury present } \\
(n=5240)\end{array}$ & \\
\hline \multicolumn{4}{|l|}{ Age (years) } \\
\hline Mean $\pm S D$ & $45.1 \pm 17.9$ & $45.9 \pm 21.2$ & 0.40 \\
\hline Gender & & & $<0.01^{*}$ \\
\hline Male & $328(74.7 \%)$ & $3403(64.9 \%)$ & \\
\hline Female & $111(25.3 \%)$ & $1837(35.1 \%)$ & \\
\hline Primary mechanism of injury & & & $<0.01^{*}$ \\
\hline Fall & $91(20.7 \%)$ & $1291(24.6 \%)$ & \\
\hline Machinery & $3(0.7 \%)$ & $43(0.8 \%)$ & \\
\hline Motor vehicle traffic & $278(63.3 \%)$ & $3248(62.0 \%)$ & \\
\hline Pedal cyclist, other & $6(1.4 \%)$ & $76(1.4 \%)$ & \\
\hline Pedestrian, other & $2(0.5 \%)$ & $28(0.5 \%)$ & \\
\hline Struck by, against & $8(1.8 \%)$ & $275(5.2 \%)$ & \\
\hline Transport, other & $51(11.6 \%)$ & $279(5.3 \%)$ & \\
\hline \multicolumn{4}{|l|}{ Injury Severity Score } \\
\hline Mean $\pm S D$ & $19.7 \pm 12.2$ & $18.2 \pm 11.5$ & $0.01^{*}$ \\
\hline \multicolumn{4}{|l|}{ Revised Trauma Score } \\
\hline Mean $\pm S D$ & $7.1 \pm 1.7$ & $7.3 \pm 1.6$ & $0.03^{*}$ \\
\hline Hypotension at admission & & & 0.60 \\
\hline Hypotension (<90 mm Hg) & $40(9.1 \%)$ & $439(8.4 \%)$ & \\
\hline No hypotension ( $\geq 90 \mathrm{~mm} \mathrm{Hg}$ ) & $399(90.9 \%)$ & $4801(91.6 \%)$ & \\
\hline Pulse rate at admission & & & 0.12 \\
\hline$>100 \mathrm{bpm}$ & $158(36.0 \%)$ & $1678(32.0 \%)$ & \\
\hline 60-100 bpm & $263(59.9 \%)$ & 3307 (63.1\%) & \\
\hline$<60$ bpm & $18(4.1 \%)$ & $255(4.9 \%)$ & \\
\hline \multicolumn{4}{|l|}{ Respiratory rate at admission } \\
\hline Mean \pm SD & $18.4 \pm 8.0$ & $18.3 \pm 6.9$ & 0.84 \\
\hline Glasgow Coma Scale at admission & & & $0.01^{*}$ \\
\hline Minor (13-15) & $363(82.7 \%)$ & $4587(87.5 \%)$ & \\
\hline Moderate (9-12) & $16(3.6 \%)$ & $138(2.6 \%)$ & \\
\hline Severe (3-8) & $60(13.7 \%)$ & $515(9.8 \%)$ & \\
\hline \multicolumn{4}{|l|}{ Abdominal organ injured } \\
\hline Adrenal gland & $439(100.0 \%)$ & $0(0.00 \%)$ & $<0.01^{*}$ \\
\hline Stomach & $2(0.5 \%)$ & $40(0.8 \%)$ & 0.47 \\
\hline Small intestine & $20(4.6 \%)$ & $316(6.0 \%)$ & 0.21 \\
\hline Colon or rectum & $16(3.6 \%)$ & $287(5.5 \%)$ & 0.10 \\
\hline Liver & $173(39.4 \%)$ & $1694(32.3 \%)$ & $0.002^{*}$ \\
\hline Spleen & $91(20.7 \%)$ & $2516(48.1 \%)$ & $<0.01^{*}$ \\
\hline Kidney & $119(27.1 \%)$ & $990(18.9 \%)$ & $<0.01^{*}$ \\
\hline Other gastrointestinal organ & $39(8.9 \%)$ & $506(9.7 \%)$ & 0.60 \\
\hline Bile duct/gall bladder & $3(0.7 \%)$ & $15(0.3 \%)$ & 0.16 \\
\hline Peritoneum & $0(0.00 \%)$ & $0(0.00 \%)$ & - \\
\hline Retroperitoneum & $40(9.1 \%)$ & $611(11.7 \%)$ & 0.11 \\
\hline Discharge status & & & 0.37 \\
\hline Died & $28(6.4 \%)$ & $396(7.6 \%)$ & \\
\hline Discharged alive & 411 (93.6\%) & 4844 (92.4\%) & \\
\hline
\end{tabular}

Data presented as $n(\%)$ unless otherwise specified.

${ }^{*} \mathrm{P}<0.05$.

$\mathrm{bpm}$, beats per minute; $\mathrm{mm} \mathrm{Hg}$, millimeter of mercury; rpm, respirations per minute.

blood pressure), and the abdominal organs injured. Hypotension at admission was determined from the systolic blood pressure and defined as $<90 \mathrm{~mm} \mathrm{Hg}$. Pulse rate at admission was categorized as $<60$ beats per minute (bpm), $60 \mathrm{bpm}$ to $100 \mathrm{bpm}$, and $>100 \mathrm{bpm}$. Respiratory rate at admission was measured as respirations per minute. The admission GCS was categorized into minor (13 to 15 ), moderate (9 to 12 ), and severe (3 to 8 ). Online supplementary figure 2 lists the ICD-9-CM codes used to identify the injured abdominal organs in each patient. The outcome of interest was in-hospital mortality and defined as a discharge status of "patient death."

The PTOS does not contain American Association for the Surgery of Trauma organ injury scale (OIS) grades or laterality/ bilaterality information. Instead it contains ICD-9 codes for organ injuries, which maps to AIS severity. AIS-1 correlates to OIS adrenal injury grades 1 and 2; AIS-2 correlates to OIS adrenal injury grades 3 and 4); and AIS-3 correlates to OIS adrenal injury grade 5 , with the understanding that the upgrading due to bilateral injury cannot be assessed.

\section{Statistical analysis}

Characteristics between patients with a blunt adrenal gland injury (+BAGI) and without a blunt adrenal gland injury (-BAGI) were compared using descriptive statistics. Mean and SD were calculated for continuous variables. Counts and relative frequencies were calculated for categorical variables. Student's t-test, Pearson's $\chi^{2}$, and Fischer's exact test were conducted to examine statistical differences in the distribution of characteristics between the study groups.

A multivariable logistic regression analysis was conducted to compare the odds of in-hospital mortality in the + BAGI group to the -BAGI group of patients. In addition to the presence of BAGI, patient and injury factors considered for adjustment in the multivariable logistic regression analysis included age, gender, mechanism of injury, ISS, RTS, and admission pulse rate. Each candidate variable's association with in-hospital mortality was assessed in an unadjusted logistic regression model. Variables that were significantly associated with in-hospital mortality were included as covariates in the final multivariable logistic regression model. Age, ISS, and RTS were treated as continuous variables. The presence of BAGI, gender, mechanism of injury, and pulse rate at admission were treated as categorical variables. For mechanism of injury, the categories of "machinery," "pedal cyclist, other," "pedestrian, other," "struck by, against," and "transport, other" were collapsed into one category named "other" due to their small individual cell counts. The specification of the final adjusted model compared with the unadjusted model containing the presence of BAGI as the sole predictor was assessed using the $\log$ likelihood ratio test. The fit of the final adjusted model was assessed using the Hosmer-Lemeshow goodness-of-fit test. ORs of in-hospital mortality and their accompanying 95\% CI were calculated for each factor in the unadjusted and adjusted logistic regression models. No interaction effects were analyzed.

A p value less than 0.05 was defined as statistically significant. All statistical analyses were performed using SAS V.9.4 (SAS Institute, Cary, North Carolina, USA).

\section{RESULTS}

The PTOS registry contained 122334 patient records from 2012 to 2014. Based on the inclusion and exclusion criteria, the final study sample was 5679 patients; 439+BAGI patients and 5240 -BAGI patients(online supplementary figure 3 ).

Table 1 presents a comparison of patient characteristics between the study groups. Liver and kidney injuries were more prevalent in the +BAGI group (liver $39.4 \%$ vs $32.3 \%, p=0.002$; kidney $27.1 \%$ vs $18.9 \%, \mathrm{p}<0.0001)$ and spleen injury was more prevalent in the -BAGI group $(48.1 \%$ vs $20.7 \%, \mathrm{p}<0.0001)$. Mortality rates were similar between the two groups. 


\begin{tabular}{|c|c|c|c|}
\hline AIS grade (OIS grade) & $\begin{array}{l}\text { Adrenal gland } \\
\text { injury }(n=439)\end{array}$ & $\begin{array}{l}\text { No adrenal gland } \\
\text { injury }(n=5240)\end{array}$ & $P$ value \\
\hline Adrenal injury & & & $\mathrm{N} / \mathrm{A}$ \\
\hline $1(1-2)$ & $429(97.7 \%)$ & - & \\
\hline $2(3-4)$ & $9(2.1 \%)$ & - & \\
\hline $3(5)$ & $1(0.2 \%)$ & - & \\
\hline No injury & $0(0.0 \%)$ & - & \\
\hline Liver injury & & & $<0.01$ \\
\hline $2(1-2)$ & $107(24.4 \%)$ & $1261(24.1 \%)$ & \\
\hline $3(3)$ & $40(9.1 \%)$ & $255(4.9 \%)$ & \\
\hline $4(4)$ & $16(3.6 \%)$ & $122(2.3 \%)$ & \\
\hline $5(5)$ & $9(2.1 \%)$ & $52(1.0 \%)$ & \\
\hline $6(6)$ & $1(0.2 \%)$ & $4(0.1 \%)$ & \\
\hline No Injury & $266(60.6 \%)$ & 3546 (67.7\%) & \\
\hline Kidney injury & & & $<0.01$ \\
\hline $2(1-2)$ & $97(22.1 \%)$ & 761 (14.5\%) & \\
\hline $3(3)$ & $9(2.1 \%)$ & $144(2.8 \%)$ & \\
\hline $4(4)$ & $6(1.4 \%)$ & $74(1.4 \%)$ & \\
\hline $5(5)$ & $7(1.6 \%)$ & $11(0.2 \%)$ & \\
\hline No injury & $320(72.9 \%)$ & $4250(81.1 \%)$ & \\
\hline Spleen injury & & & $<0.01$ \\
\hline $2(1-2)$ & 67 (15.3\%) & $1515(28.9 \%)$ & \\
\hline $3(3)$ & $13(3.0 \%)$ & $542(10.3 \%)$ & \\
\hline $4(4)$ & $6(1.4 \%)$ & 327 (6.2\%) & \\
\hline $5(5)$ & $5(1.1 \%)$ & $132(2.5 \%)$ & \\
\hline No injury & 348 (79.3\%) & 2724 (52.0\%) & \\
\hline
\end{tabular}

The distribution of the severity of adrenal gland injuries and the solid organs in proximity to the adrenal glands, the liver, kidneys and spleen, was compared between the +BAGI and -BAGI groups. Since nearly $98 \%$ of the adrenal gland injuries were AIS-1/OIS Grade 1 to 2, no attempt was made to stratify based on the magnitude of the adrenal gland injury (table 2).

Liver injuries were more frequent in + BAGI patients, although the frequency of AIS-2 (OIS Grade 3/4) between the two groups virtually identical $(24.4 \%$ vs $24.1 \%)$. Injuries of the kidney were also more frequent in the +BAGI group, with a $50 \%$ increase in AIS-2 (OIS Grade 3/4) injuries as compared with the -BAGI group. Splenic injuries were far more frequent among -BAGI patients in total and for each AIS. Overall, the incidence of severe solid organ injury was similar between the two groups (table 3 ).

Table 4 presents the unadjusted and adjusted OR estimates of in-hospital mortality of the +BAGI group to the -BAGI group from logistic regression analysis. Unadjusted logistic regression models found that age, mechanism of injury, ISS, RTS, and admission pulse were all significantly associated with in-hospital

\begin{tabular}{lllc}
\hline $\begin{array}{l}\text { Table } 3 \\
\text { injury }\end{array}$ & Distribution of concurrent severe liver, kidney, and spleen \\
\hline & $\begin{array}{l}\text { Adrenal gland } \\
\text { injury } \\
(\mathbf{n}=439)\end{array}$ & $\begin{array}{l}\text { No adrenal gland } \\
\text { injury } \\
(\mathbf{n}=5240)\end{array}$ & P value \\
\hline Severe liver injury & $26(5.9 \%)$ & $178(3.4 \%)$ & $0.0063^{*}$ \\
\hline Severe kidney injury & $13(3.0 \%)$ & $85(1.6 \%)$ & $0.0385^{*}$ \\
\hline Severe spleen injury & $11(2.5 \%)$ & $459(8.8 \%)$ & $<0.0001^{*}$ \\
\hline Severe liver/kidney/spleen injury & $49(11.2 \%)$ & $697(13.3 \%)$ & 0.2023 \\
\hline
\end{tabular}

Severe Injury: AIS Severity $\geq 4$.

${ }^{*} \mathrm{P}<0.05$.
Table 4 Risk factor OR estimates of in-hospital mortality from unadjusted and adjusted logistic regression analyses

\begin{tabular}{|c|c|c|c|c|}
\hline & \multicolumn{2}{|c|}{ Unadjusted } & \multicolumn{2}{|c|}{ Adjusted } \\
\hline & OR & $95 \% \mathrm{Cl}$ & OR & $95 \% \mathrm{Cl}$ \\
\hline \multicolumn{5}{|l|}{ Abdominal injury } \\
\hline Adrenal gland injury & 0.83 & 0.56 to 1.24 & 0.62 & 0.37 to 1.04 \\
\hline No adrenal gland injury (ref) & - & - & - & - \\
\hline Age & 1.02 & 1.01 to $1.02^{*}$ & 1.05 & 1.05 to $1.06^{*}$ \\
\hline \multicolumn{5}{|l|}{ Gender } \\
\hline Male & 0.99 & 0.81 to 1.22 & & \\
\hline Female (ref) & - & - & & \\
\hline \multicolumn{5}{|l|}{ Mechanism of injury } \\
\hline Motor vehicle traffic & 3.70 & 2.36 to $5.79^{*}$ & 1.32 & 0.76 to 2.27 \\
\hline Fall & 1.96 & 1.20 to $3.22^{*}$ & 0.95 & 0.52 to 1.73 \\
\hline Other (ref) $\dagger$ & - & - & - & - \\
\hline Injury Severity Score & 1.10 & 1.09 to $1.11^{*}$ & 1.07 & 1.06 to $1.08^{*}$ \\
\hline Revised Trauma Score & 0.51 & 0.48 to $0.53^{*}$ & 0.56 & 0.53 to $0.60^{*}$ \\
\hline \multicolumn{5}{|l|}{ Pulse rate at admission } \\
\hline$>100$ bpm & 2.02 & 1.60 to $2.54^{*}$ & 1.50 & 1.13 to $2.01 *$ \\
\hline$<60$ bpm & 16.04 & 12.01 to 21.41 * & 4.62 & 2.91 to $7.34^{*}$ \\
\hline 60-100 bpm (ref) & - & - & - & - \\
\hline \multicolumn{5}{|l|}{ Model performance statistics } \\
\hline$-2 \log L$ & \multicolumn{2}{|l|}{$3015.062 \ddagger$} & \multicolumn{2}{|c|}{1672.729} \\
\hline H-L GOF $p$ value & & & 0.065 & \\
\hline
\end{tabular}

${ }^{* *} \mathrm{P}<0.05$.

†"Other" category includes: machinery; pedal cyclist, other; pedestrian, other; struck by, against; transport, other.

$\$ 2$ Log $\mathrm{L}$ value from unadjusted logistic regression model containing adrenal injury as predictor variable.

bpm, beats per minute; H-L GOF, Hosmer-Lemeshow goodness-of-fit; -2LogL, -2 Log likelihood statistic; ref, reference category.

mortality and were thus selected as covariates to be included the final adjusted model. In the unadjusted analysis, the odds of in-hospital mortality was $17 \%$ lower in the +BAGI group, but this reduction was not statistically significant (OR: $0.83,95 \%$ CI 0.56 to 1.24$)$. After controlling for age, ISS, RTS and pulse, the odds of in-hospital mortality was 38\% lower in the +BAGI group, but again this reduction was not statistically significant (OR: 0.62 , 95\% CI 0.37 to 1.04 ).

Age, ISS, RTS, and admission pulse rate were all found to be significantly associated with in-hospital mortality in the adjusted logistic regression analysis. The odds of in-hospital mortality increased 5\% for each year increase in the patient's age $(95 \%$ CI 1.05 to 1.06 ), increased $7 \%$ for each point increase in the patient's ISS (95\% CI 1.06 to 1.08), and decreased 44\% for each point reduction in the patient's RTS ( $95 \%$ CI 0.53 to 0.60$)$. The odds of in-hospital mortality was $50 \%$ higher in patients with an admission pulse rate greater than $100 \mathrm{bpm}$ (OR: 1.13 to 2.01) and $362 \%$ higher in patients with an admission pulse rate less than 60 bpm (OR: 2.91 to 7.34) compared with patients with an admission pulse rate between 60 and $100 \mathrm{bpm}$. Evaluation of the log likelihood ratio test and the Hosmer-Lemeshow Goodnessof-Fit test showed that the adjusted logistic regression model was both adequately specified and fit.

\section{DISCUSSION}

The PTOS Registry of the Pennsylvania Trauma System Foundation was chosen for analysis because of the completeness of this registry and the geographic and demographic similarities between New York and Pennsylvania. ${ }^{10-12}$ The incidence of BAGI 

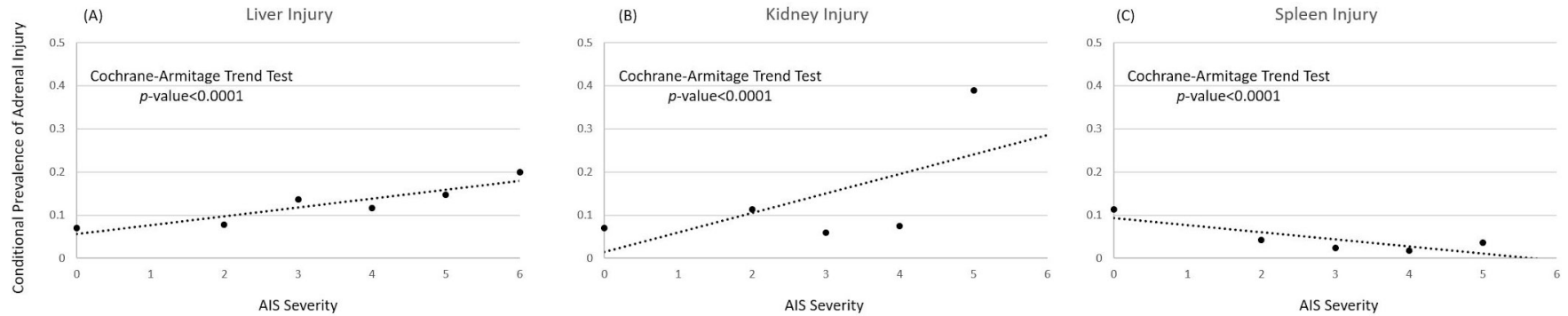

Figure 1 Prevalence of adrenal injury by AIS severity score. AIS, Abbreviated Injury Score.

in Pennsylvania was $0.43 \%$, compared with $0.61 \%$ for New York and $0.52 \%$ for our single institution.?

The average ISS was 19.7 for +BAGI and 18.2 for -BAGI. We do not consider this statistically significant difference $(p=0.008)$ to be clinically significant.

The mortality rate for + BAGI patients of $6.4 \%$ was not significantly different from the -BAGI cohort of $7.2 \%$. These findings are similar to the mortality rates from the NYSTR of $6.6 \%$ and $8.2 \%$, which were also not statistically different.

The overwhelming majority of BAGIs (97.7\%) were AIS-1, or grade 1 to 2 . Previous studies which identified BAGIs at autopsy, laparotomy, or by low resolution CT scan likely missed the majority of these injuries. ${ }^{2-6} 13$ Their conclusions that BAGI is associated with an increased severity of injury and mortality are based on an over-representation of grade 3, 4, and 5 injuries.

The abdominal organs most frequently injured in both + BAGI and-BAGI patients were liver, kidney, and spleen (table 2). The incidences of these organ injuries mirror previous reports for + BAGI and -BAGI groups. ${ }^{45714}$ Severe injuries (AIS $\geq 4$ ) of the liver and kidneys were more frequent among + BAGI patients whereas severe injuries of the spleen were less frequent. The clinical importance lies not in the frequency of severe injuries to these organs individually, but that the overall incidence of severe injury to any solid organ is the same, whether there are associated injuries to the adrenal gland or not (table 3 ). This obviates an unequal distribution of severe solid organ injuries as a cause of differences in +BAGI and -BAGI mortality.

Previous single institution reports have shown a marked predominance of right adrenal gland injuries over left, with bilateral injuries occurring rarely. Unfortunately, the PTOS registry does not contain laterality data for bilateral organs, so we are unable to make such an assessment in this study. A review of eight large series demonstrate that right-sided injuries constitute $72.8 \%$ of blunt adrenal gland injuries, left $19.9 \%$, and bilateral $7.3 \%$ (table 5 ).
We think the reason for the marked right/left discrepancy is the venous anatomy of each gland. Within each gland are two circulatory patterns. In the cortical portions of the body and tail, the straight capsular arteries are interrupted by a plexus, the vascular dam. The head and body have portal systems of valveless venous sinuses between the cortex and medullary tissue which empty directly into a central vein, which is short and drains directly into the inferior vena cava (IVC) on the right, but is longer and joins the left inferior phrenic vein before entering the renal vein on the left. ${ }^{15-17}$ This right versus left side difference is important when considering the three major mechanisms of injury which have been proposed: (1) direct injury through direct transfer of energy from the point of blunt impact to the organ; (2) deceleration-related injury with internal shearing of the adrenal gland tissues; and (3) injury through water-hammer transfer of increased IVC pressure, as occurs with sudden forcible compression of the abdomen.

Clearly direct injury of the adrenal glands occurs. ${ }^{3-6} 13141819$ We identified the prevalence of BAGI increased with increased AIS of the liver and kidney, which are adjacent (figure 1). The decreased prevalence of BAGI with increased spleen AIS is expected because the vector of the direct energy transfer necessary to injure the spleen would be more lateral on the torso as compared with the kidneys and central area of the liver.

The biomechanics and pathophysiology of deceleration injuries from motor vehicle crashes and falls result in shearing of the juxtamedullary venous sinuses, causing the hematoma found in the head and body of the adrenal gland. This was the finding in the first case of traumatic adrenal injury reported by Grisellius in 1670 and more recent reports. ${ }^{2021}$

Increased central venous pressure is the third proposed mechanism of injury. ${ }^{2122}$ It is the etiology of adrenal hemorrhage in newborns and mothers after especially arduous deliveries and after adrenal venography. ${ }^{23-27}$ Increased pressure in the IVC can be directly transmitted into the venous sinuses of the medullary

Table 5 Summary of laterality and associated injuries

\begin{tabular}{|c|c|c|c|c|c|c|c|c|}
\hline \multirow[b]{2}{*}{ Author } & \multirow[b]{2}{*}{ Total patients } & \multicolumn{3}{|c|}{ Adrenal injury } & \multicolumn{4}{|c|}{ Associated injuries (\%) } \\
\hline & & Right & Left & Bilateral & Ribs & Liver & Spleen & Kidney \\
\hline Burks et $a l^{13}$ & 20 & 12 & 5 & 3 & $12(60.0)$ & $5(25.0)$ & $8(40.0)$ & $6(30.0)$ \\
\hline Rana et $a^{\beta}$ & 51 & 39 & 9 & 3 & $33(64.7)$ & $26(51.0)$ & $24(47.1)$ & $16(31.4)$ \\
\hline Mehrazin et $a l^{4}$ & 130 & 99 & 25 & 6 & $88(67.7)$ & $54(41.5)$ & 35 (26.9) & $36(27.7)$ \\
\hline Sinelnikov et a $/^{5}$ & 73 & 56 & 11 & 6 & Not Reported & $31(42.5)$ & $17(23.3)$ & $13(17.8)$ \\
\hline Stawicki et a/ ${ }^{6}$ & 29 & 16 & 12 & 1 & $20(69.0)$ & $7(24.1)$ & $11(37.9)$ & $4(13.8)$ \\
\hline Alsayali et a/14 & 96 & 70 & 22 & 4 & Not Reported & $30(31.2)$ & $20(20.8)$ & $24(25.0)$ \\
\hline Liao et a $/^{18}$ & 77 & 59 & 16 & 2 & $37(48.1)$ & $51(66.2)$ & Not reported & $33(42.9)$ \\
\hline Panda et a $/^{19}$ & 47 & 30 & 4 & 13 & Not Reported & $22(46.8)$ & $10(21.3)$ & $5(10.6)$ \\
\hline Total & 523 & 381 (72.8\%) & 104 (19.9\%) & $38(7.3 \%)$ & $61.9 \%(190 / 307)$ & $43.2 \%(226 / 523)$ & $28.0 \%(125 / 446)$ & $26.2 \%(137 / 523)$ \\
\hline
\end{tabular}


tissue below the vascular dam, leading to overdistension and rupture. The right adrenal gland with its short vein and direct IVC communication is more susceptible to this mechanism of injury than the left with its intervening branches which can dissipate a sudden increase in IVC pressure.

The latter two mechanisms explain delayed development of adrenal gland hematomas, a phenomenon previously reported in the liver and spleen. ${ }^{13} 1928-31$

We are unable to address the associated incidence of adrenal insufficiency in this population as the PTOS database only contains injury diagnosis codes. A limited and select list of complications are reported not as ICD-9 codes, but as dichotomous flags (Yes/No), of which adrenal insufficiency is not one.

Our limitations include those of any retrospective review of an aggregated registry. Seven per cent of the study sample records were excluded because of missing essential data fields. This had a significant impact on the statistical analysis as the missing data fields were random. Further, as a consequence of ICD-9 codes being used to identify injuries in the PTOS database, it is only possible to analyze the AIS grade of the BAGI and not the OIS grade or the laterality/bilaterality of the injured organ. This obligatory lack of granularity limits the depth to which analysis is possible. Further investigations into this aspect of blunt adrenal gland injury may require a multi-institutional collaborative effort. Details of the equipment used to perform CT are also not available from this registry, including the generation and resolution capacity.

\section{CONCLUSION}

The traditional dogma on BAGIs has been that they are rare, associated with high morbidity, and highly mortal. This retrospective review of the PTOS Registry is consistent with recent smaller reviews and demonstrates that the incidence is higher than previously thought, about $0.5 \%$, but that the consequences are negligible. ${ }^{1718}$ Blunt force injury of the adrenal gland is not associated with increased morbidity or an elevated mortality rate.

Contributors JCD and LDGA provided conception and design, interpretation, article development, and critical review. NG and SC-S provided data collection and article development. SM provided statistical analysis and critical review.

Funding The authors have not declared a specific grant for this research from any funding agency in the public, commercial or not-for-profit sectors.

Competing interests None declared.

Patient consent for publication Not required.

Ethics approval This study was reviewed by the Nassau University Medical Center Institutional Review Board, protocol number 16-096, as exempt.

Provenance and peer review Not commissioned; externally peer reviewed.

Data availability statement Data may be obtained from a third party and are not publicly available. These data were provided by the Pennsylvania trauma systems foundation, Mechanicsburg, Pennsylvania, USA. The foundation specifically disclaims responsibility for any analyses, interpretations, or conclusions.

Open access This is an open access article distributed in accordance with the Creative Commons Attribution Non Commercial (CC BY-NC 4.0) license, which permits others to distribute, remix, adapt, build upon this work non-commercially, and license their derivative works on different terms, provided the original work is properly cited, appropriate credit is given, any changes made indicated, and the use is non-commercial. See: http://creativecommons.org/licenses/by-nc/4.0/.

ORCID ID

Jody C DiGiacomo http://orcid.org/0000-0002-8452-309X

\section{REFERENCES}

1 DiGiacomo JC, Angus LDG, Coffield E. Adrenal injuries: historical facts and modern truths. World J Surg 2017:41:975-9.

2 Sevitt S. Post-traumatic adrenal apoplexy. J Clin Pathol 1955;8:185-94.

3 Rana Al, Kenney PJ, Lockhart ME, McGwin G, Morgan DE, Windham ST, Smith JK. Adrenal gland hematomas in trauma patients. Radiology 2004;230:669-75.

4 Mehrazin R, Derweesh IH, Kincade MC, Thomas AC, Gold R, Wake RW. Adrenal trauma: ELVIS Presley Memorial trauma center experience. Urology 2007;70:851-5.

5 Sinelnikov AO, Abujudeh HH, Chan D, Novelline RA. CT manifestations of adrenal trauma: experience with 73 cases. Emerg Radiol 2007:13:313-8.

6 Stawicki SP, Seamon MJ, Carvalho CM, Bhoot N, Sharma R, Schrag SP, Steinberg SM. Adrenal gland injury secondary to blunt traumatic mechanisms: a marker of overall injury severity. Endokrynol Pol 2009;60:2-8.

7 DiGiacomo JC, Gerber N, Angus LDG, Munnangi S, Cardozo-Stolberg S. Blunt adrenal injury: results of a state trauma registry review. Am Surg 2019;85:390-6.

8 Pennsylvania Trauma Systems Foundation. 2018 operational manual for the data base collection system. 2018. http://ptsf.org/upload/7-25-18_FINAL_2018_PTOS_Manual. pdf (29 Aug 2019).

9 The American Association for the Surgery of Trauma. Injury scoring scale. http://www. aast.org/Library/TraumaTools/InjuryScoringScales.aspx (29 Aug 2019).

10 https://countryeconomy.com/countries/usa-states/compare/newyork/pennsylvania (Accessed 8/29/2019)

11 https://www.indexmundi.com/facts/united-states/quick-facts/compare/newyork. pennsylvania (Accessed on 8/29/2019).

12 https://www.fs.usda.gov/naspf/sites/default/files/featuredprojects/20160311_fm_ctnj nypahighlandsfpb508.pdf (Accessed 8/29/2019).

13 Burks DW, Mirvis SE. Shanmuganathan K: acute adrenal injury after blunttrauma: CT findings. American Journal of Radiology 1992;158:503-7.

14 Alsayali MM, Atkin C, Rahim R, Niggemeyer LE, Doody O, Varma D. Traumatic adrenal gland injury: epidemiology and outcomes in a major Australian trauma center. Eur $J$ Trauma Emerg Surg 2010;36:567-72.

15 Gray H. Anatomy, descriptive and surgical. New York: Bounty Books, 1988:996-8.

16 Dobbie JW, Symington T. The human adrenal gland with special reference to the vasculature. J Endocrinol 1966:34:479-NP.

17 Pick JW, Anson BJ. The inferior phrenic artery: origin and suprarenal branches. Anat $\operatorname{Rec} 1940 ; 78: 413-27$

18 Liao C-H, Ouyang C-H, Fu C-Y, Wang S-Y, Lin K-J, Kuo I-M, Hsu C-P, Yang S-J, Yuan $\mathrm{K}-\mathrm{C}$, Hsu Y-P. The current status and management of blunt adrenal gland trauma. Surgery 2015;157:338-43

19 Panda A, Kumar A, Gamanagatti S, Bhalla AS, Sharma R, Kumar S, Mishra B. Are traumatic bilateral adrenal injuries associated with higher morbidity and mortality?-A prospective observational study. J Trauma Manag Outcomes 2015;9:6.

20 Greiselius JG: ren succenturiatus monstrosus, cum ulcere. Miscellanea CuriosaMedicophysica. Page 152-153. Leipzig; 1670.

21 Scully RE, Mark EJ. Mcneely BU: case records of the Massachusetts GeneralHospital. Weekly clinicopathological exercises. Case 38-1984. Hypertension and anadrenal mass after a vehicular accident. New England Journal of Medicine 1984:311:783-90.

22 Wilms G, Marchal G, Baert A, Adisoejoso B, Mangkuwerdojo S. Ct and ultrasound features of post-traumatic adrenal hemorrhage. J Comput Assist Tomogr 1987;11:112-5.

23 Bookstein JJ, Conn J, Reuter SR. Intra-Adrenal hemorrhage as a complication of adrenal venography in primary aldosteronism. Radiology 1968;90:778-9.

24 Melby JC. Identifying the adrenal lesion in primary aldosteronism. Ann Intern Med 1972:76:1039-41.

25 Velaphi SC, Perlman JM. Neonatal adrenal hemorrhage: clinical and abdominal sonographic findings. Clin Pediatr 2001:40:545-8.

26 Gyurkovits Z, Maróti Ágnes, Rénes L, Németh G, Pál A, Orvos H, Maroti A. Adrenal haemorrhage in term neonates: a retrospective study from the period 2001-2013. The Journal of Maternal-Fetal \& Neonatal Medicine 2015;28:2062-5.

27 Wani MS, Naikoo ZA, Malik MA, Bhat AH, Wani MA, Oadri SA. Spontaneous adrenal hemorrhage during pregnancy: review of literature and case report of successful conservative management. J Turk Ger Gynecol Assoc 2011;12:263-5.

28 Oto A, Ozgen B, Akhan O, Besim A. Delayed posttraumatic adrenal hematoma. Eur Radiol 2000;10:903-5.

29 Agrawal N, Rao S, Zellweger R, Knight T. Adrenal pseudoaneurysm due to blunt trauma. Indian J Surg 2013;75:155-7.

30 Gates JD. Delayed hemorrhage with free rupture complicating the nonsurgical management of blunt hepatic trauma: a case report and review of the literature. $J$ Trauma 1994:36:572-5.

31 DiGiacomo JC, Rotondo MF, Kauder DR, Schwab CW. Delayed splenic hematoma: an injury in evolution. Surgery 1998:123:478-9. 